\title{
Estudos mostram limite e potencial
}

\section{da televisão *}

\section{Esther Hamburqer}

Três livros publicados este ano expressam o esforço contemporâneo por entender o papel da televisão na produção de conhecimento. Editados na Inglaterra, um dos mais importantes centros de pesquisa sobre o assunto, estes livros marcaram a superação de concepções que limitavam papel da televisão ao de reproduzir ideologias.

Alguns dos mais importantes professores de comunicações se aventuraram a pensar processos concretos de criação para além da posição reducionista entre dominação ou resistência a conteúdos pressupostos, que tem marcado o pensamento sobre o assunto. Escritos no contexto de avaliação da avalanche de estudos de recepção que marcou os últimos quinze anos, e livres da necessidade de se posicionar contra ou a favor do meio televisivo, os autores mantêm uma postura crítica.

Informados pela demonstração empírica já bastante reprisada de que os conteúdos de programas televisivos não estão totalmente determinados no texto, mas estão sujeitos a uma certa diversidade de interpretação, alguns autores investigam essa diversidade.

"Television and Common Knowledge", editado por Jostein Gripsrud, professor de estudos de mídia da Universidade de Bergen na Noruega, reúne textos novos de estudiosos de referência. John Ellis, por exemplo, expõe um modelo teórico em que pretende definir a TV como mecanismo de transformação de dados da realidade em formas narrativas.

É como se a televisão trabalhasse um assunto à exaustão, uma exaustão que não é conclusiva. Trata-se de uma especulação contínua, mas não totalizante, de assuntos. $\mathrm{O}$ autor descreve esse processo nos diversos gêneros.

Autor de um conhecido estudo etnográfico de 1983 sobre a feitura de um documentário d BBC, Silverstone volta ao tema. Baseado em seu estudo anterior de inspiração estruturalista e com ênfase na análise do texto, e na crítica ao que caracteriza como relativismo exagerado dos estudos de recepção, o autor se propõe agora a focalizar a interação entre espectador e texto.

O ensaio de David Morley, autor conhecido por seus trabalhos sobre recepção de televisão em contextos familiares, discute a pouca relevância que a notícia televisiva tem na vida de telespectadores ingleses. $\mathrm{O}$ autor retoma a inquietação de pioneiros no estudo da mídia como Merton e Lazarsfeld sobre o que eles chamaram de "disfunções narcotizantes" do excesso de informações para analisar depoimentos de espectadores contemporâneos que demonstraram pouco interesse e baixo nível de compreensão do noticiário político. Contrastando essa falta de interesse pela notícia, Morley chama a atenção para a ambigüidade, a polissemia e a contradição do gênero.

"Uses of Television", de John
* Texto originalmente publicado na Folha de São Paulo, Caderno Folha llustrada, p.4/6, 4/02/1999, e reproduzido pela Novos Olhares com autorização da Folha de São Paulo e da autora.

Esther Hamburger é professora junto à ECA/USP. 
Hartley, diretor da Escola de Jornalismo, Culture e Society", revisa as principais Mídia e Estudos Culturais da Univeridéias sobre o papel da televisão em sidade de Cardiff e autor, como John tomo da imagem, narrativa, recepção, Fiske, de "Reading Television", trabalho prazer, conhecimento.

que representou um dos primeiros

A publicação dos três livros indica esforços para compreender o papel da televisão na vida cotidiana das telespectadores, recoloca, 20 anos depois, a mesma problemática. Hartley parte do que é uma constatação básica para se entender o papel da televisão: a idéia de que a sociedade de consumo, mediada por novas tecnologias de comunicação, a política e a educação pública se interpenetram.

"Criticai Ideas in Television Studies" de John Comer, professor da Escola Política e Estudos de Comunicação da Universidade de Liverpool uma certa efervescência na área. John Hartley aponta o acúmulo de estudos nos últimos 20 anos, o que indicaria a formação de um campo de "estudos de televisão". É possível notar o amadurecimento dos estudos sobre televisão, a sofisticação teórica crescente. A preocupação entre os três livros aponta uma direção promissora para a investigação dos limites e potencialidades da televisão. E que pode ajudar a entender os mistérios da produção do conhecimento e da cultura na sociedade de massas.

e um dos editores da revista "Media

\section{Bibliografia do Artigo}

GRIPSRUD,Jostein. Television and Common Knowledge. Inglaterra, Editora Routledge, 1999.

HARTLEY, John. Uses of Television. Inglaterra, Editora Routledge, 1999.

CORNER, John. Criticai Ideas in Television Studies. Inglaterra, Routledge, 1999. 